\title{
Therapeutic potential of egg yolk antibodies for treating Clostridium difficile infection
}

\author{
Correspondence \\ G. D. Armstrong \\ glen.armstrong@ucalgary.ca
}

Received 31 December 2010

Accepted 5 April 2011

\author{
G. L. Mulvey, ${ }^{1} \dagger$ T. C. Dingle, ${ }^{1} \dagger$ L. Fang, ${ }^{2}$ J. Strecker ${ }^{1}$ and G. D. Armstrong ${ }^{1}$ \\ ${ }^{1}$ University of Calgary, Calgary, Alberta, Canada \\ ${ }^{2}$ Zyme Fast Inc., Oak Bank, Manitoba, Canada
}

\begin{abstract}
Herein we present evidence for the therapeutic potential of colonization factor (CF)-specific egg yolk antibodies (IgY) for potentially treating acute and recurring Clostridium difficile infection (CDI) in humans. The study involved cloning, expressing as $6 \times$ His-tagged proteins in Escherichia coli, and Ni-affinity purifying three previously identified CFs (FliC, FliD and Cwp84) from C. difficile. The recombinant $\mathrm{CF}$ antigens were then used to immunize Leghorn chickens and CF-specific IgY antibodies were prepared from their eggs. The specificity and titre of the resulting C. difficile CF-specific IgY antibodies were assessed by ELISA and Western immunoblotting techniques. The antibodies were also screened for their ability to inhibit C. difficile adherence to human colon-derived T84 cells, and, based on these findings, one of them (FliD-specific lgY) was evaluated for its potential to prevent C. difficile-mediated morbidity and mortality in Syrian hamsters. The results revealed that purified FliD-specific lgY significantly protected hamsters from C. difficile strain 630 infection relative to control animals treated with carbonate buffer alone or IgY produced from unimmunized chicken eggs. The results suggest that egg yolk preparations obtained from chickens immunized with recombinant $C$. difficile CFs may represent another safe and cost-effective treatment option in humans suffering from acute or recurring CDI.
\end{abstract}

\section{INTRODUCTION}

Conventional antibiotics alter both the numbers and complexity of the normal gastrointestinal (GI) microflora, thereby reducing the ability of these protective organisms to competitively exclude opportunists from colonizing the GI tract. This disruption may render hospitalized subjects susceptible to colonization by C. difficile (Job \& Jacobs, 1997). Once established in the colon, C. difficile expresses two very large exotoxins, toxin $A(\operatorname{Tcd} A)$ and toxin B $(\mathrm{TcdB})$, which are primarily responsible for the clinical symptoms of $C$. difficile infection (CDI) (Voth \& Ballard, 2005). These range from diarrhoea to pseudomembranous colitis, toxic megacolon and multi-system organ failure, which may be fatal.

The accepted approach to treating CDI is to replace the antibiotic responsible for initiating the condition with one, typically metronidazole, to which $C$. difficile is sensitive. In about $80 \%$ of cases, this approach leads to complete recovery without further complications. In the remaining cases, however, recurring $\mathrm{CDI}$ (rCDI) can occur, due, presumably, to a failure of the normal GI microflora to become re-established after the metronidazole is

†These authors contributed equally to this work.

Abbreviations: $\mathrm{CDI}$, Clostridium difficile infection; $\mathrm{CF}$, colonization factor; $\mathrm{Gl}$, gastrointestinal; IgY, egg yolk antibodies; rCDI, recurring $\mathrm{C}$. difficile infection; TcdA/TcdB, C. difficile toxin A/toxin B. discontinued. This leaves the colon of these individuals susceptible to $C$. difficile relapse or reinfection. Multiple recurrences are not unusual, resulting in a significant reduction in the quality of life in these individuals.

In response to the increasing risk of CDI to human health, much research has focused on new and improved treatment regimens, particularly in subjects suffering from rCDI. These studies have concentrated on novel toxin neutralizing agents, antibiotics which are more sparing of the normal GI microflora, and pre- or probiotic approaches (Aboudola et al., 2003; Giannasca \& Warny, 2004; Kelly et al., 1996; Kink \& Williams, 1998; McFarland, 2009; Merrigan et al., 2009; Monaghan et al., 2009).

Although much is known about the role of TcdA and TcdB in CDI pathogenesis, relatively less is known about the role, if any, of intestinal colonization by $C$. difficile. There are indications, however, that $C$. difficile does colonize the mammalian GI tract. For example, subjects asymptomatically colonized by $C$. difficile display a decreased risk of developing CDI and pre-colonizing clindamycin-treated hamsters with non-toxigenic $C$. difficile strains protected the animals from a subsequent challenge with a wild-type toxigenic strain (Merrigan et al., 2003; Sambol et al., 2002). In addition, convalescent sera from human CDI subjects contain antibodies to $C$. difficile cell wall-associated components (e.g. FliC, FliD, Fbp68, SlpA, Cwp66 and Cwp84) that have been implicated in the organism's 
colonization strategy in vitro (Calabi et al., 2001, 2002; Hennequin et al., 2003; Karjalainen et al., 1994, 2001; Tasteyre et al., 2001a; Wright et al., 2005, 2008). Consequently, we wished to determine the efficacy of a colonization-targeted immunotherapeutic approach to treating CDI as well as preventing rCDI.

The investigations reported herein utilized egg yolk antibodies (IgY) specific to three putative $C$. difficile colonization factors $(\mathrm{CFs})$ and vaccine candidates (Péchiné et al., 2005): the flagellar structural protein (flagellin), FliC, flagellar cap protein, FliD, and an $84 \mathrm{kDa}$ cell wallassociated cysteine protease, Cwp84, which has been implicated in the proper processing and assembly of the surface layer protein, SlpA (Kirby et al., 2009). We contend that CF-specific IgY preparations, either alone or in combination with other therapeutic strategies, represent attractive candidates for treating CDI because they can be mass-produced inexpensively and they are listed in the generally regarded as safe category for human use. There is also ample evidence that purified IgG (Kelly et al., 1996) and IgY (Kink \& Williams, 1998) antibodies retain their inhibitory activity after passage through the stomach and small intestine of many mammals. CF-specific IgY preparations should also facilitate eliminating $C$. difficile from the intestines of CDI sufferers while, at the same time, sparing the normal GI microflora and consequently reduce incidences of rCDI.

\section{METHODS}

C. difficile strains and culture methods. C. difficile strain 630 was kindly provided by Dr Trevor Lawley at the Wellcome Trust Sanger Institute. C. difficile strain VPI 10463 (ATCC 43255) was obtained from the American Type Culture Collection (Manassas, VA, USA). The C. difficile strains were routinely grown on Y agar plates [brainheart infusion (BHI) agar containing $5 \%$ sheep blood, $5 \mathrm{mg}$ haemin and $1 \mathrm{mg}$ vitamin $\mathrm{K} \mathrm{l}^{-1}$ ] from frozen stocks and incubated anaerobically in a Bactron III anaerobic chamber (Shel Lab) for $48 \mathrm{~h}$ at $37^{\circ} \mathrm{C}$. In the adherence assays, single colonies were inoculated into BHI culture medium and incubated at $37{ }^{\circ} \mathrm{C}$ anaerobically for $18 \mathrm{~h}$, until cultures reached the late-exponential phase of growth.

The C. difficile 630 fliC gene disruption mutant strain (Cdi-fliC-260a) used to validate the swim agar assay was constructed in our laboratory using the ClosTron group II intron-based mutagenesis system as previously described by Heap et al. (2007). Western immunoblot analysis, transmission electron microscopy and the agar tube swim assay revealed that this $f l i C$ gene disruption mutant strain lacked the ability to produce flagellin (FliC) as well as assemble functional flagellar filaments (data not shown).

Human intestine-derived T84 cell culture conditions. T84 human colon-derived cells (ATCC CCL-248) were routinely used between passage numbers 40 and 60 and cultured at $37^{\circ} \mathrm{C}$ in $5 \% \mathrm{CO}_{2}$ in $24-$ well tissue culture plates using Dulbecco's minimal Eagle's medium/ Nutrient Mixture F12 (DMEM/F12) supplemented with $10 \%$ fetal bovine serum.

Cloning the FliC, FliD and Cwp84 antigens. The fliC, fliD and cwp84 genes were PCR-amplified from an ermB, Clin ${ }^{\mathrm{r}}$, ribotype 001, North American pulsotype 2 C. difficile Calgary Laboratory Services clinical isolate \#2007 provided by Dr Thomas Louie (Department of Medicine, University of Calgary). The PCR primers were designed as described previously (Savariau-Lacomme et al., 2003; Tasteyre et al., 2000, 2001b) but lacking the 5' restriction sites. Next, the PCR products were cloned into pQE-30 UA (Qiagen) following the manufacturer's instructions. The clones were then transformed into Escherichia coli M15 cells using standard chemical transformation protocols. Expression and purification of the $6 \times$ His-tagged proteins was performed according to the manufacturer's protocols for the pQE-30 cloning system. The purified proteins were analysed by SDSPAGE ( $12.5 \%$ separating gels) (Fig. 1) and their identity was positively confirmed by mass spectroscopic analysis of tryptic peptides produced from the protein bands excised from the gels.

Chicken immunization protocol. The antigen preparations containing $0.1 \mathrm{mg}$ of each Ni-affinity-purified $6 \times$ His-tagged recombinant antigen in $0.5 \mathrm{ml}$ PBS ( $\mathrm{pH}$ 7.2) were emulsified in Freund's complete adjuvant $(1: 1)$ and injected intramuscularly into the breast muscles of 5-month-old white Leghorn chickens. Two weeks after the first injection, chickens received booster injections of the same dosage by the same route of administration and this was repeated 2 weeks later. Freund's incomplete adjuvant was used in place of the complete adjuvant for the second and third injections. The eggs were collected 1 week after the final injection and stored at $2-4{ }^{\circ} \mathrm{C}$ until they were processed.

Purification of CF-specific IgY from lyophilized egg yolk. IgY was purified from lyophilized egg yolk powder essentially as described by Ko \& Ahn (2007). Briefly, 2 g lyophilized egg yolk powder was dissolved in $150 \mathrm{ml}$ ice-cold distilled water. The mixture was

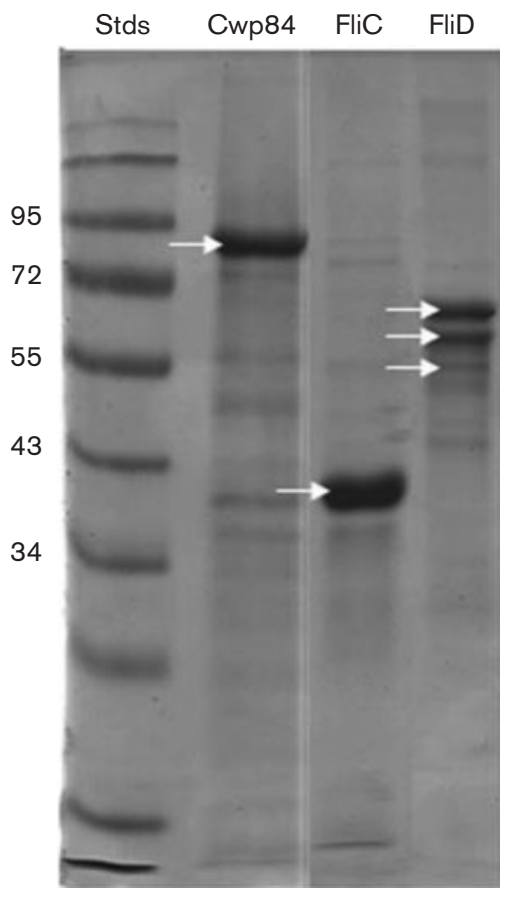

Fig. 1. Coomassie brilliant blue-stained SDS-PAGE (12.5\% separating gel) gel analysis of recombinant $6 \times$ His-tagged $C$. difficile Ni-affinity-purified FliC, FliD and Cwp84. Molecular masses of standard proteins used to calibrate the gel are shown in $\mathrm{kDa}$ next to the first lane on the left. Arrows indicate the gel bands sent for mass spectrometric sequence determination. 
homogenized for 1 min at high speed using a Waring blender and the $\mathrm{pH}$ was subsequently adjusted to 5.0. Following a $40 \mathrm{~min}$ centrifugation step at $2800 \mathrm{~g}$, the $\mathrm{pH}$ of the supernatant solution was adjusted to 4.0 and charcoal was added to a final concentration of $0.01 \%$ $(\mathrm{w} / \mathrm{v})$. The supernatant solution from a second $30 \mathrm{~min} 2800 \mathrm{~g}$ centrifugation step was filtered through Whatman number 1 filter paper. The filtrate was concentrated to $30 \mathrm{ml}$ using an Amicon cell stirrer fitted with a $100 \mathrm{kDa}$ molecular mass cut-off membrane. The concentrated IgY solution was adjusted to $\mathrm{pH} 9.0$ and the protein was precipitated by adding $40 \%$ ammonium sulfate for $1 \mathrm{~h}$ at $4{ }^{\circ} \mathrm{C}$. The solution was then centrifuged at $3000 \mathrm{~g}$ for $30 \mathrm{~min}$. The resulting ammonium sulfate pellet was dissolved in $15 \mathrm{ml} 0.01 \mathrm{M}$ Tris/ $\mathrm{HCl}$, $\mathrm{pH} 8.0$, and the IgY was again precipitated by $40 \%$ ammonium sulfate for $1 \mathrm{~h}$ at $4{ }^{\circ} \mathrm{C}$. After a final centrifugation step at $3000 \mathrm{~g}$ for $30 \mathrm{~min}$, the pellet was dissolved in sodium/potassium PBS ( $\mathrm{pH} 7.2)$ and dialysed overnight into PBS using a $50 \mathrm{kDa}$ molecular mass cutoff dialysis membrane.

SDS-PAGE and Western immunoblotting. Recombinant $6 \times$ Histagged FliC, FliD and Cwp84 were Ni-affinity purified from E. coli and resolved by SDS-PAGE using $12.5 \%$ separating gels. Next, the separated proteins were electrophoretically transferred to PVDF membranes for $45 \mathrm{~min}$ at $200 \mathrm{~V}$. The blots were then blocked using $5 \%$ skim milk dissolved in Tris-buffered ( $\mathrm{pH} 7.4$ ) physiological saline containing $0.05 \%$ Tween 20 (TBSTM). Primary IgY antibodies were diluted in TBSTM and incubated with the membranes for $1 \mathrm{~h}$. Goat anti-IgY secondary antibody conjugated to horseradish peroxidase (Sigma-Aldrich) was then added at a 1:10000 dilution in TBSTM and incubated with the membrane for $1 \mathrm{~h}$. After thoroughly washing the membranes with TBST (TBSTM lacking 5\% skim milk), immunoreactive proteins were visualized using the SuperSignal West Dura Extended Duration Substrate as instructed by the supplier (Thermo Scientific) and the images were captured on a Kodak Image Station 2000MM.

C. difficile swim agar assay. Swim agar tubes contained a final concentration of $0.175 \%$ agar in BHI. IgY antibodies were added to a final concentration of $10 \mathrm{mg} \mathrm{ml}^{-1}$. The C. difficile 630 and fliC gene disruption mutant strains from overnight cultures were stabbed vertically into the agar. The tubes were then incubated anaerobically for $24 \mathrm{~h}$ at $37^{\circ} \mathrm{C}$.

Hamster protection experiments. The hamster CDI protocol was reviewed and approved by the University of Calgary Health Sciences Animal Care Committee (protocol ID\# M08122) and the experiments were performed according to the 1993 guidelines published by the Canada Council on Animal Care. Male Syrian hamsters (Harlan laboratories) weighing between 80 and $100 \mathrm{~g}$ were treated on day -5 with clindamycin phosphate dissolved in PBS by gavage at a dose of $30 \mathrm{mg}$ (kg body weight) ${ }^{-1}$. Five days thereafter (day 0 ), the animals received, by gavage, $10^{3} \mathrm{C}$. difficile strain 630 spores suspended in DMEM/F12. Hamsters treated with the egg yolk from unimmunized chickens received $45 \mathrm{mg}$ of the lyophilized powder suspended in $0.5 \mathrm{ml} 0.1 \mathrm{M}$ carbonate buffer $(\mathrm{pH} 9.0)$ beginning on day 0 and then daily thereafter for a period of 10 days. Those treated with purified FliD-specific IgY only, received $0.5 \mathrm{mg}$ protein, determined using the bicinchoninic acid assay, in $0.5 \mathrm{ml}$ bicarbonate buffer daily for 10 days. Animals treated with purified FliD-specific IgY reconstituted in egg yolk from unimmunized chickens received the equivalent amount of FliD-specific IgY ( $0.5 \mathrm{mg}$ protein) plus $45 \mathrm{mg}$ lyophilized egg yolk powder in $0.5 \mathrm{ml}$ bicarbonate buffer daily for 10 days. The hamsters were monitored continuously every $4 \mathrm{~h}$ and immediately euthanized by $\mathrm{CO}_{2}$ asphyxia when signs of CDI (perianal staining, unresponsiveness) appeared.

Immunogold labelling procedure. A single C. difficile 630 colony was suspended in a solution of $2 \%$ formaldehyde $/ 0.5 \%$ glutaraldehyde prepared in $50 \mathrm{mM}$ sodium cacodylate buffer $(\mathrm{pH} 7.4)$ for $20 \mathrm{~min}$ anaerobically. Ten microlitres of fixed bacteria was then applied to a carbon-coated transmission electron microscopy grid (Electron Microscopy Sciences) for 2 min and excess solution was gently wicked away using filter paper. Blocking was performed by floating the grid sample side down on a $50 \mu$ drop of $5 \%$ BSA in PBS for $1 \mathrm{~h}$. The grid was then transferred to a $50 \mu \mathrm{l}$ drop of a 1:50 dilution of FliD-specific or control IgY diluted in 5\% BSA for $1 \mathrm{~h}$. After thorough washing with PBS, the grid was transferred to a $50 \mu \mathrm{l}$ drop of a $1: 25$ dilution of goat anti-IgY conjugated to $15 \mathrm{~nm}$ gold particles (Abcam) for $1 \mathrm{~h}$. After washing with PBS, the grid was stained by adding a $10 \mu \mathrm{l}$ drop of $1 \%$ phosphotungstic acid (pH 7.0) for $10 \mathrm{~s}$. Excess stain was gently wicked away using filter paper and the dried grids were examined using a Hitachi H-7650 transmission electron microscope.

T84 cell C. difficile adherence assay. All experiments were performed in triplicate. C. difficile strain VPI 10463 cultures in the late-exponential phase $\left(\mathrm{OD}_{600}=0.65\right)$ of growth were diluted in overnight pre-reduced DMEM/F12 containing CF-specific or control egg yolk IgY preparation $\left(1 \mathrm{mg} \mathrm{ml}{ }^{-1}\right)$ and added to T84 cell monolayers at a concentration of approximately $10^{6}$ c.f.u. $\mathrm{ml}^{-1}$ (m.o.i.=1:1). The tissue culture plates were incubated at $37^{\circ} \mathrm{C}$ anaerobically for $3 \mathrm{~h}$ and then washed five times with sterile PBS to remove non-adherent organisms. Viability of the T84 cells after $3 \mathrm{~h}$ of anaerobiosis was assessed using the MTT [3-(4,5-dimethylthiazol-2yl)-2,5-diphenyltetrazolium] cell proliferation assay (Mosmann, 1983). To determine the number of adherent bacteria, the T84 cells were treated with $0.25 \%$ trypsin containing $1 \mathrm{mM}$ EDTA and then diluted tenfold in sterile PBS. Dilutions were subsequently plated in triplicate on $\mathrm{Y}$ agar plates. The plates were incubated anaerobically at $37{ }^{\circ} \mathrm{C}$ for $48 \mathrm{~h}$ and the resulting colonies were counted at a dilution resulting in 30-300 colonies per plate.

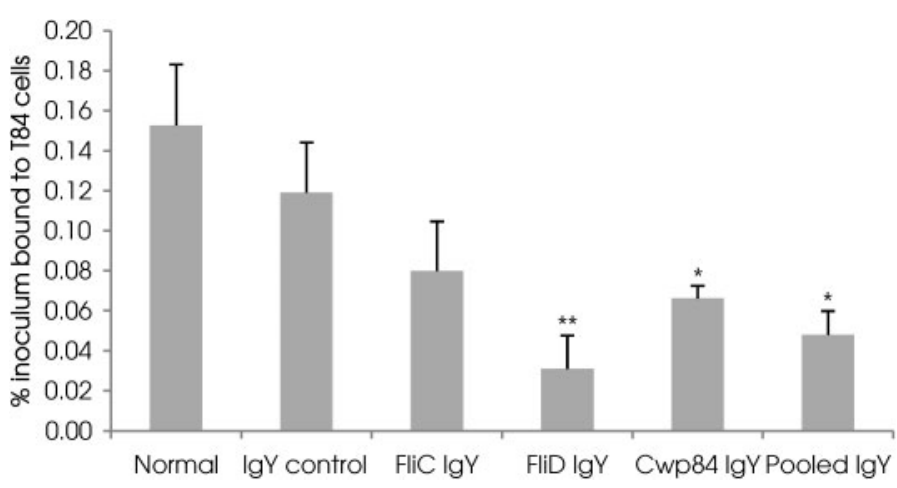

http://jmm.sgmjournals.org
Fig. 2. Effect of lyophilized egg yolk preparations containing CF-specific lgY on C. difficile (VPI 10463) adherence to colon-derived T84 tissue culture cells. The final concentration of protein in each egg yolk preparation was $1 \mathrm{mg}$ $\mathrm{ml}^{-1}$. The column labelled 'Normal' represents the data obtained in the absence of egg yolk. The experiment was performed in triplicate and the error bars indicate the standard deviations ( ${ }^{\star} P<0.05,{ }^{\star \star} P<0.001$, Student's $t$-test). 


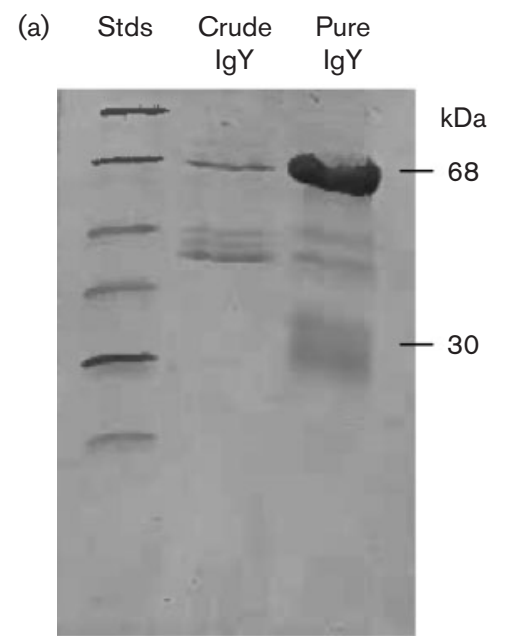

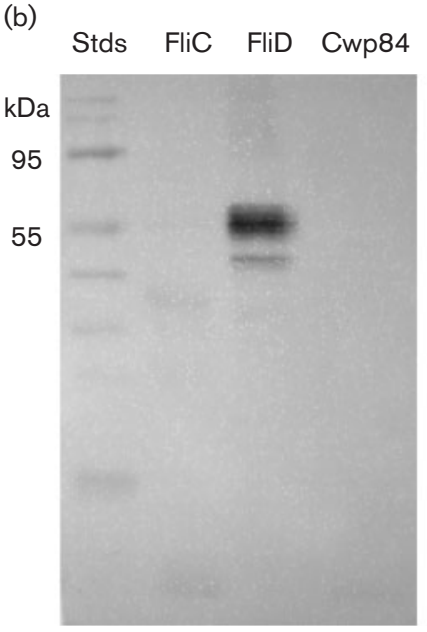

$1^{\circ} \mathrm{Ab}=$ Anti-FliD

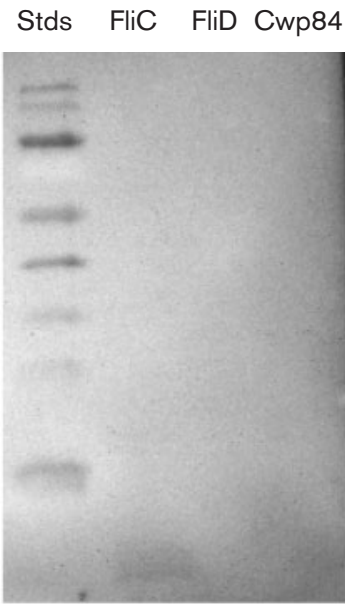

$1^{\circ} \mathrm{Ab}=$ Control $\lg \mathrm{Y}$

Fig. 3. (a) SDS-PAGE analysis of FliD-specific IgY purified according to the method of Ko \& Ahn (2007). Coomassie brilliant blue-stained $12.5 \%$ separating gel. (b) Western immunoblots of recombinant $6 \times$ His-tagged C. difficile FliC, FliD and Cwp84 using FliD-specific $\lg \mathrm{Y}\left(1^{\circ} \mathrm{Ab}\right)$ and horseradish peroxidase-conjugated goat anti-lgY $\left(2^{\circ} \mathrm{Ab}\right)$. The FliD-specific $\lg \mathrm{Y}$ was diluted $1: 100000$.

\section{RESULTS}

Fig. 1 is an image of an SDS-PAGE gel on which we analysed the Ni-affinity-purified recombinant $C$. difficile FliC, FliD and Cwp84 antigens used to immunize the chickens. The indicated bands (arrows) were excised from the gel and used to confirm the identity of the three purified proteins by mass spectroscopic analysis. This also confirmed that all three bands visible in the FliD preparation represented intact in addition to truncated sequences of the FliD protein.

Yolks obtained from eggs laid by chickens immunized with recombinant $C$. difficile FliC, FliD or Cwp84 were initially screened for their ability to inhibit the adherence of $C$. difficile strain VPI 10463 to human colon-derived T84 cell monolayers under anaerobic conditions. The results (Fig. 2) of these experiments revealed that egg yolks containing FliD-specific IgY inhibited the adherence of $C$. difficile to T84 cell monolayers significantly better than either those from unimmunized chickens $(P<0.001$, Student's $t$-test) or those containing FliC-specific IgY $(P<0.05$, Student's $t$-test). Although a $1: 1: 1$ by weight mixture of all three CF-specific egg yolk preparations inhibited $C$. difficile adherence to T84 cells significantly $(P<0.05$, Student's $t$-test) better than FliC-specific egg yolk alone, mixing the three preparations did not result in an improvement of the inhibition relative to that caused by the FliD-specific preparation. We therefore selected egg yolks containing FliD-specific IgY for further evaluation.

FliD-specific IgY was purified from lyophilized egg yolks using the two-step charcoal de-lipidation ammonium sulfate precipitation process previously reported by Ko \& Ahn (2007). SDS-PAGE analysis (Fig. 3a) revealed that IgY purified using this simple and efficient procedure resulted in predominantly two bands which migrated to positions characteristic of proteins having molecular masses of 68 and $30 \mathrm{kDa}$ and representing the IgY heavy and light chains, respectively (Warr et al., 1995). The results presented in Fig. 3(b) revealed that the purified FliDspecific IgY preparation bound to the FliD antigen in Western immunoblots and that it did not cross-react with either the FliC or Cwp84 antigens. Further, an

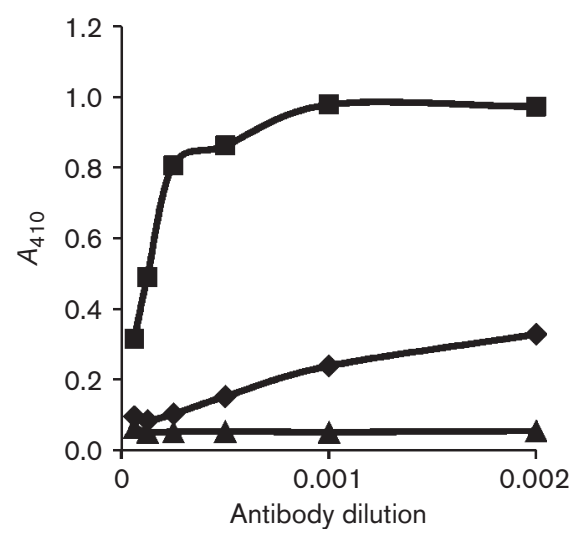

Fig. 4. Analysis of crude lyophilized egg yolk containing FliDspecific $\lg Y$ and purified FliD-specific $\lg Y$ by an antigen capture ELISA. Antibodies were diluted twofold beginning from $30 \mathrm{mg}$ $\mathrm{ml}^{-1}$ and used to detect $100 \mathrm{ng}$ pure FliD antigen coated onto a 96-well plate. The control was a lyophilized yolk preparation obtained from eggs laid by unimmunized chickens. FliD $\lg Y$ crude; $\mathbf{\square}$, FliD IgY pure; $\mathbf{\Delta}$, control lgY. 


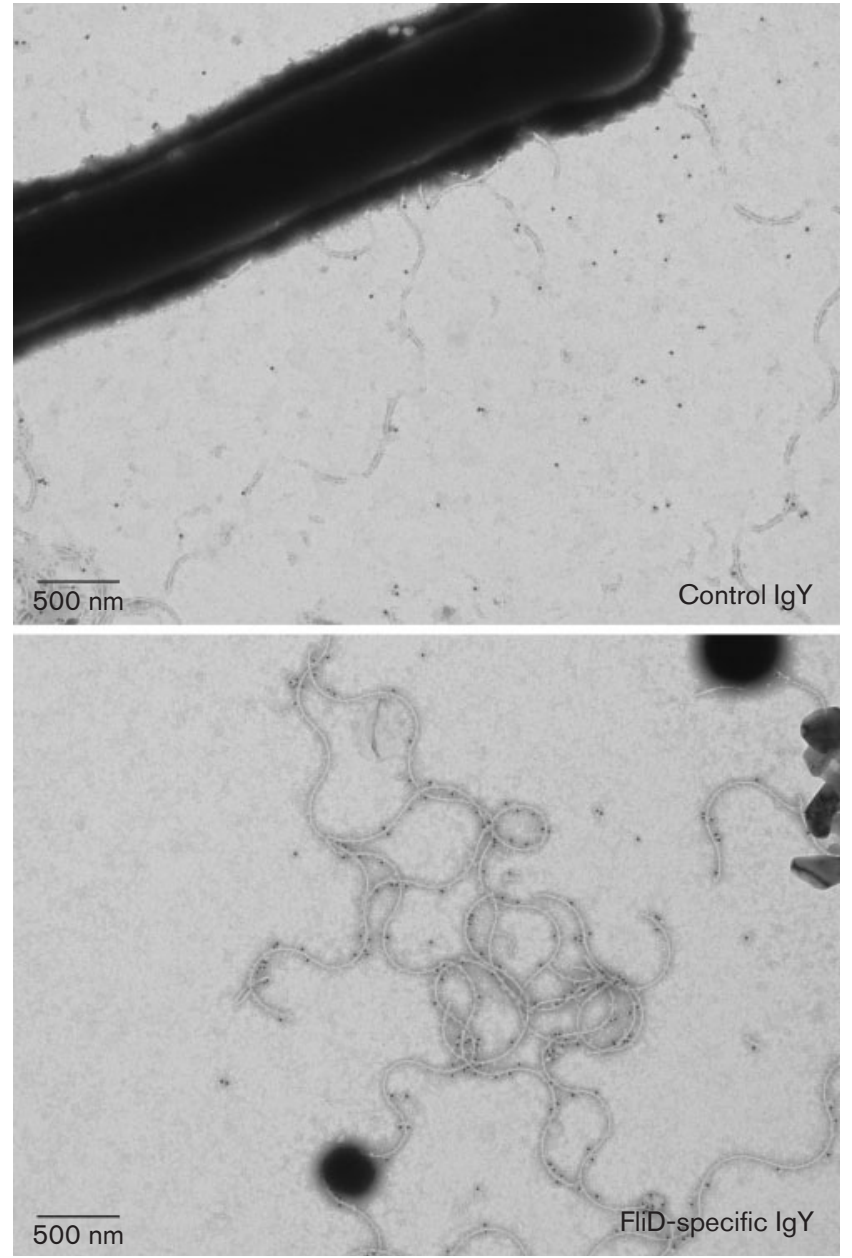

Fig. 5. Immunogold labelling of C. difficile (630) flagella using purified FliD-specific $\lg Y$ or control IgY purified from eggs laid by unimmunized chickens.

antigen-capture-based ELISA indicated that purifying the FliD-specific IgY from lyophilized egg yolk significantly improved its titre relative to that of the crude FliD-specific egg yolk preparations (Fig. 4). The transmission electron micrographs in Fig. 5 demonstrate that the FliD-specific IgY preparations bound to $C$. difficile flagella as revealed by the immunogold labelling technique whereas control IgY egg yolk did not. In addition, the FliD-specific IgY preparation reduced the motility of $C$. difficile strain 630 as revealed in the swim agar assay compared to swim agar containing control IgY or lacking IgY altogether (Fig. 6).

The cumulative survival results from five independent hamster CDI protection experiments are presented in Fig. 7. These data demonstrate that purified FliD-specific IgY in carbonate buffer alone significantly $(P<0.05$, two-tailed Fisher's exact test) increased the survival of hamsters challenged with $10^{3} \mathrm{C}$. difficile 630 spores relative to animals that received control egg yolk from unimmunized chickens. Moreover, reconstituting purified FliD-specific

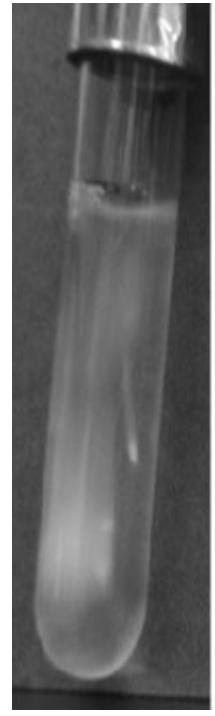

C. difficile 630

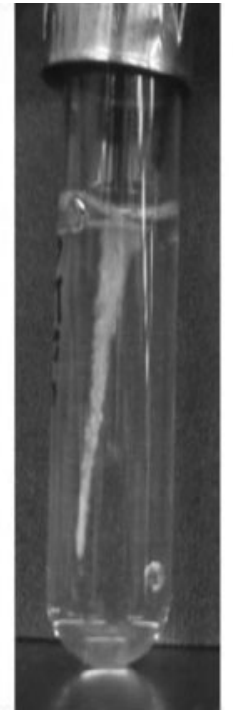

fliC mutant

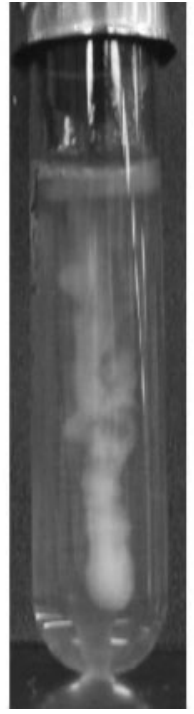

$+10 \mathrm{mg} \mathrm{ml}^{-1}$ FliD-specific lgY

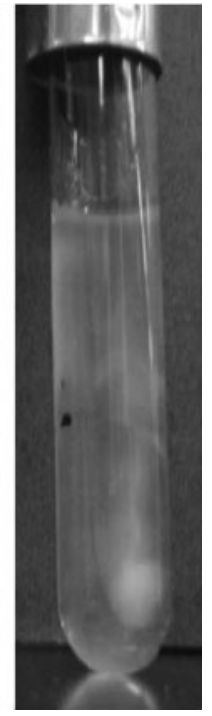

$+10 \mathrm{mg} \mathrm{ml}^{-1}$ Control lgY
Fig. 6. Swim agar assay. C. difficile 630 was stab-inoculated into swim agar tubes containing $10 \mathrm{mg}$ purified control or FliD-specific $\lg \mathrm{Y} \mathrm{ml}^{-1}$. The $\triangle \mathrm{FliC}$ C. difficile (630) strain (Cdi-fliC-260a) was a fliC disruption mutant created using the ClosTron system (Heap et al., 2010).

IgY with control egg yolk did not significantly change its protective efficacy in the hamster CDI experiments.

\section{DISCUSSION}

Given their central role in pathogenesis, innovative intervention strategies directed at neutralizing only TcdA and $\mathrm{TcdB}$ have been tried, but with a modicum of success, to treat CDI in humans (Weiss, 2009).We therefore wished to test the hypothesis that regimens targeting other $C$. difficile virulence factors may prove to be more effective CDI treatments or adjunct treatments. In a previous report, Tasteyre et al. (2001a) presented evidence demonstrating that FliD adhered to a preparation of murine caecal mucus, suggesting that this flagellar component may act as a $C$. difficile adhesin in addition to its role in regulating flagellar assembly and their function in motility. Another study conducted by Péchiné et al. (2005) indicated that subjects suffering from CDI produced serum antibodies to C. difficile FliD, FliC, Fpb68, a fibronectin-binding protein, and Cwp66. They also demonstrated that CDI subjects produced a more vigorous immune response to $C$. difficile FliD relative to FliC. They attributed this difference to less antigenic variability in FliD, which, the authors posit, is consistent with its additional potential role as a $C$. difficile adhesin.

The results presented herein establish the feasibility of using IgY specific for the $C$. difficile FliD flagellar cap protein as an alternative or adjunct approach to treating subjects suffering from CDI or rCDI. The observation that 


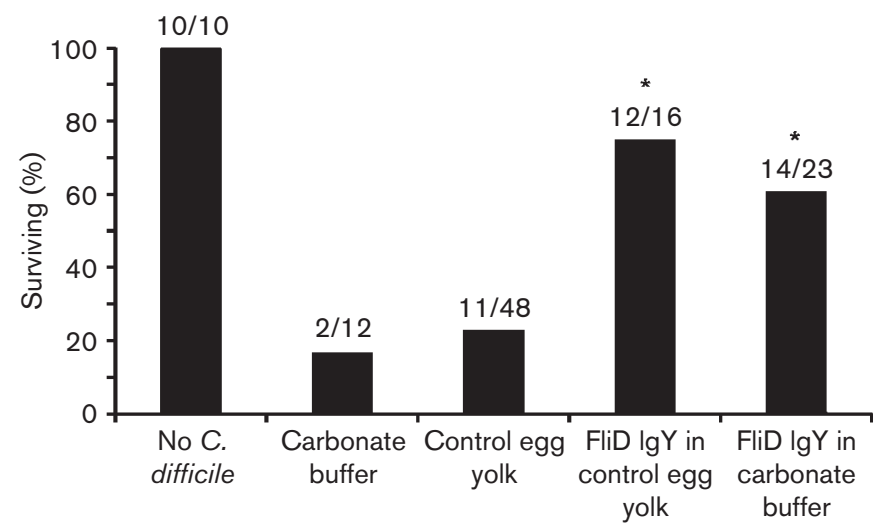

Fig. 7. Cumulative results from five independent hamster CDI protection experiments. In each experiment, all the hamsters were treated with clindamycin phosphate $\left[30 \mathrm{mg}\left(\mathrm{kg}\right.\right.$ body weight) $\left.{ }^{-1}\right] 5$ days prior to receiving $10^{3} \mathrm{C}$. difficile (630) spores by gavage. At the same time as the $C$. difficile spores were administered, the hamsters received, by gavage, $0.5 \mathrm{ml}$ carbonate buffer alone, control yolk powder from eggs laid by unimmunized chickens ( $45 \mathrm{mg}$ in $0.5 \mathrm{ml}$ carbonate buffer), purified FliD-specific lgY ( $0.5 \mathrm{mg}$ protein in $0.5 \mathrm{ml}$ carbonate buffer) or an equivalent amount of purified FliD-specific lgY reconstituted into $45 \mathrm{mg}$ control egg yolk in $0.5 \mathrm{ml}$ carbonate buffer. Sentinel animals (no C. difficile) remained uninfected and untreated. The animals were treated once per day for a period of 10 days. *Significant differences $(P<0.05)$ determined relative to group receiving control egg yolk using the two-tailed Fisher's exact test.

the FliD-specific IgY preparation provided good protection from CDI in hamsters correlated with the superior action of these antibodies in inhibiting $C$. difficile from adhering to human colon-derived T84 cells (Fig. 2). This observation also supports the conclusions from the two previous studies (Péchiné et al., 2005; Tasteyre et al., 2001a) into the role of FliD in the $C$. difficile colonization strategy. However, we did not assess the $C$. difficile colonization rates in the hamster protection experiments so we can only assume that the enhanced survival correlated with a lower colonization rate in the FliD-specific IgY-treated animals.

In addition to its important role in the C. difficile colonization process, the success of the FliD-specific IgY preparation in treating CDI in hamsters may be related to the high avidity that these antibodies appear to have for their epitopes as well as the number of epitopes accessible to them on the FliD protein. The reactivity in the Western immunoblots, even at a dilution of 100000 times (Fig. 3b), of the FliD-specific IgY preparation is testament to the avidity of these polyclonal antibodies for the epitopes expressed on the FliD antigen. High avidity of the IgY preparation may also represent an advantage should a significant proportion of the antibodies be digested during passage through the GI track of the host. It may not matter how much of the preparation remains physically intact and active upon arriving at the intestinal site of the infection if the proportion of the material that does survive is still capable of incapacitating the pathogenic organism.

\section{ACKNOWLEDGEMENTS}

This study was funded by a CIHR Industry-Partnered (Zyme Fast Inc.) Grant to G.D.A. and by the Alberta Ingenuity Centre for
Carbohydrate Science. T. C. D. is the recipient of an NSERC Canada Graduate Scholarship.

\section{REFERENCES}

Aboudola, S., Kotloff, K. L., Kyne, L., Warny, M., Kelly, E. C., Sougioultzis, S., Giannasca, P. J., Monath, T. P. \& Kelly, C. P. (2003). Clostridium difficile vaccine and serum immunoglobulin $\mathrm{G}$ antibody response to toxin A. Infect Immun 71, 1608-1610.

Calabi, E., Ward, S., Wren, B., Paxton, T., Panico, M., Morris, H., Dell, A., Dougan, G. \& Fairweather, N. (2001). Molecular characterization of the surface layer proteins from Clostridium difficile. Mol Microbiol 40, 1187-1199.

Calabi, E., Calabi, F., Phillips, A. D. \& Fairweather, N. F. (2002). Binding of Clostridium difficile surface layer proteins to gastrointestinal tissues. Infect Immun 70, 5770-5778.

Giannasca, P. J. \& Warny, M. (2004). Active and passive immunization against Clostridium difficile diarrhea and colitis. Vaccine 22, 848-856.

Heap, J. T., Pennington, O. J., Cartman, S. T., Carter, G. P. \& Minton, N. P. (2007). The ClosTron: a universal gene knock-out system for the genus Clostridium. J Microbiol Methods 70, 452-464.

Heap, J. T., Cartman, S. T., Kuehne, S. A., Cooksley, C. \& Minton, N. P. (2010). ClosTron-targeted mutagenesis. Methods Mol Biol 646, 165-182.

Hennequin, C., Janoir, C., Barc, M. C., Collignon, A. \& Karjalainen, T. (2003). Identification and characterization of a fibronectin-binding protein from Clostridium difficile. Microbiology 149, 2779-2787.

Job, M. L. \& Jacobs, N. F., Jr (1997). Drug-induced Clostridium difficile-associated disease. Drug Saf 17, 37-46.

Karjalainen, T., Barc, M. C., Collignon, A., Trollé, S., Boureau, H., Cotte-Laffitte, J. \& Bourlioux, P. (1994). Cloning of a genetic determinant from Clostridium difficile involved in adherence to tissue culture cells and mucus. Infect Immun 62, 4347-4355.

Karjalainen, T., Waligora-Dupriet, A. J., Cerquetti, M., Spigaglia, P., Maggioni, A., Mauri, P. \& Mastrantonio, P. (2001). Molecular and 
genomic analysis of genes encoding surface-anchored proteins from Clostridium difficile. Infect Immun 69, 3442-3446.

Kelly, C. P., Pothoulakis, C., Vavva, F., Castagliuolo, I., Bostwick, E. F., O'Keane, J. C., Keates, S. \& LaMont, J. T. (1996). AntiClostridium difficile bovine immunoglobulin concentrate inhibits cytotoxicity and enterotoxicity of $C$. difficile toxins. Antimicrob Agents Chemother 40, 373-379.

Kink, J. A. \& Williams, J. A. (1998). Antibodies to recombinant Clostridium difficile toxins $\mathrm{A}$ and $\mathrm{B}$ are an effective treatment and prevent relapse of $C$. difficile-associated disease in a hamster model of infection. Infect Immun 66, 2018-2025.

Kirby, J. M., Ahern, H., Roberts, A. K., Kumar, V., Freeman, Z., Acharya, K. R. \& Shone, C. C. (2009). Cwp84, a surface-associated cysteine protease, plays a role in the maturation of the surface layer of Clostridium difficile. J Biol Chem 284, 34666-34673.

Ko, K. Y. \& Ahn, D. U. (2007). Preparation of immunoglobulin Y from egg yolk using ammonium sulfate precipitation and ion exchange chromatography. Poult Sci 86, 400-407.

McFarland, L. V. (2009). Renewed interest in a difficult disease: Clostridium difficile infections - epidemiology and current treatment strategies. Curr Opin Gastroenterol 25, 24-35.

Merrigan, M. M., Sambol, S. P., Johnson, S. \& Gerding, D. N. (2003). Prevention of fatal Clostridium difficile-associated disease during continuous administration of clindamycin in hamsters. J Infect Dis 188, 1922-1927.

Merrigan, M. M., Sambol, S. P., Johnson, S. \& Gerding, D. N. (2009). New approach to the management of Clostridium difficile infection: colonisation with non-toxigenic $C$. difficile during daily ampicillin or ceftriaxone administration. Int $J$ Antimicrob Agents 33 (Suppl. 1), S46-S50.

Monaghan, T., Boswell, T. \& Mahida, Y. R. (2009). Recent advances in Clostridium difficile-associated disease. Postgrad Med J 85, 152-162.

Mosmann, T. (1983). Rapid colorimetric assay for cellular growth and survival: application to proliferation and cytotoxicity assays. J Immunol Methods 65, 55-63.
Péchiné, S., Gleizes, A., Janoir, C., Gorges-Kergot, R., Barc, M. C., Delmée, M. \& Collignon, A. (2005). Immunological properties of surface proteins of Clostridium difficile. J Med Microbiol 54, 193-196.

Sambol, S. P., Merrigan, M. M., Tang, J. K., Johnson, S. \& Gerding, D. N. (2002). Colonization for the prevention of Clostridium difficile disease in hamsters. J Infect Dis 186, 1781-1789.

Savariau-Lacomme, M. P., Lebarbier, C., Karjalainen, T., Collignon, A. \& Janoir, C. (2003). Transcription and analysis of polymorphism in a cluster of genes encoding surface-associated proteins of Clostridium difficile. J Bacteriol 185, 4461-4470.

Tasteyre, A., Barc, M. C., Karjalainen, T., Dodson, P., Hyde, S., Bourlioux, P. \& Borriello, P. (2000). A Clostridium difficile gene encoding flagellin. Microbiology 146, 957-966.

Tasteyre, A., Barc, M. C., Collignon, A., Boureau, H. \& Karjalainen, T. (2001a). Role of FliC and FliD flagellar proteins of Clostridium difficile in adherence and gut colonization. Infect Immun 69, 7937-7940.

Tasteyre, A., Karjalainen, T., Avesani, V., Delmée, M., Collignon, A., Bourlioux, P. \& Barc, M. C. (2001b). Molecular characterization of fliD gene encoding flagellar cap and its expression among Clostridium difficile isolates from different serogroups. J Clin Microbiol 39, 11781183.

Voth, D. E. \& Ballard, J. D. (2005). Clostridium difficile toxins: mechanism of action and role in disease. Clin Microbiol Rev 18, 247263.

Warr, G. W., Magor, K. E. \& Higgins, D. A. (1995). IgY: clues to the origins of modern antibodies. Immunol Today 16, 392-398.

Weiss, K. (2009). Toxin-binding treatment for Clostridium difficile: a review including reports of studies with tolevamer. Int J Antimicrob Agents 33, 4-7.

Wright, A., Wait, R., Begum, S., Crossett, B., Nagy, J., Brown, K. \& Fairweather, N. (2005). Proteomic analysis of cell surface proteins from Clostridium difficile. Proteomics 5, 2443-2452.

Wright, A., Drudy, D., Kyne, L., Brown, K. \& Fairweather, N. F. (2008). Immunoreactive cell wall proteins of Clostridium difficile identified by human sera. J Med Microbiol 57, 750-756. 